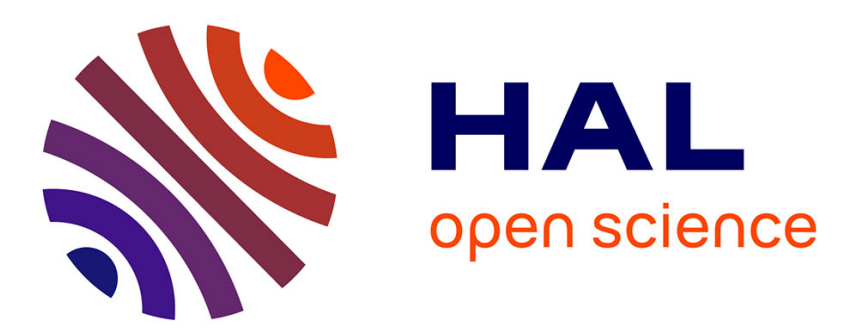

\title{
An assessment of the ecological potential of Central and Western European reservoirs based on fish communities
}

\author{
P. Blabolil, Maxime Logez, D. Ricard, M. Prchalova, M. Riha, A. Sagouis, J.
}

Peterka, J. Kubecka, C. Argillier

\section{- To cite this version:}

P. Blabolil, Maxime Logez, D. Ricard, M. Prchalova, M. Riha, et al.. An assessment of the ecological potential of Central and Western European reservoirs based on fish communities. Fisheries Research, 2016, 173, pp.80-87. 10.1016/j.fishres.2015.05.022 . hal-01235784

\section{HAL Id: hal-01235784 \\ https://hal.science/hal-01235784}

Submitted on 30 Nov 2015

HAL is a multi-disciplinary open access archive for the deposit and dissemination of scientific research documents, whether they are published or not. The documents may come from teaching and research institutions in France or abroad, or from public or private research centers.
L'archive ouverte pluridisciplinaire HAL, est destinée au dépôt et à la diffusion de documents scientifiques de niveau recherche, publiés ou non, émanant des établissements d'enseignement et de recherche français ou étrangers, des laboratoires publics ou privés. 
1 Title: An assessment of the ecological potential of Central and Western European reservoirs based on fish

2 communities

3

4 Authors: Petr Blabolil ${ }^{1,2,{ }^{*}}$, Maxime Logez ${ }^{3,4}$, Daniel Ricard ${ }^{1}$, Marie Prchalová ${ }^{1}$, Milan Ríha $^{1}$, Alban

5 Sagouis $^{3}$, Jiří Peterka ${ }^{1}$, Jan Kubečka ${ }^{1}$, Christine Argillier ${ }^{3}$

6

7 Affiliations:

$8{ }^{1}$ Biology Centre of the Czech Academy of Sciences, v.v.i., Institute of Hydrobiology, České Budějovice,

9 Czech Republic.

$10 \quad{ }^{2}$ Faculty of Science, University of South Bohemia, České Budějovice, Czech Republic

$11{ }^{3}$ Irstea, UR HYAX, Centre d'Aix-en-Provence, Pôle Onema/Irstea Hydro-écologie Plans d'Eau, F-13 182

12 Aix-en-Provence, France

$13{ }^{4}$ Aix Marseille Université, CNRS, IRD, Univ. Avignon. IMBE UMR 7263, 13397 Marseille France

14

$15{ }^{*}$ Corresponding author: Blabolil.Petr@ seznam.cz

16

17 Running title: A fish-based index to assess the eutrophication of reservoirs

18

19 Keywords: eutrophication, heavily modified water body, hindcasting, multimetric index, Water

20 Framework Directive

21

22 Abstract

23 In this study we developed a novel methodology based on fish communities to assess the ecological

24 potential of central European reservoirs. Using the hindcasting approach, our index predicts values that

25 could be observed in the absence of pressures for each reservoir depending on their environmental 

standardized benthic gillnet sampling and transformed to functional and taxonomical metrics. After all validation by multiple testing of models redundancy and pressure-response, the final index was composed of three metrics: total biomass of fish, abundance of invertivores/piscivores, and abundance of planktivorous fish. The index accurately identifies reservoirs that are lightly, moderately and heavily affected by eutrophication. In addition to French and Czech reservoirs, this index could be a useful tool

7 for countries with few reservoirs and the basis for further collaborative studies.

1. Introduction

Reservoirs are artificial water bodies, classified as heavily modified water bodies (HMWB) under the

11 Water Framework Directive (WFD) and in many areas they replace natural lakes. Similarly to lakes,

12 HMWB are subject to anthropogenic stressors. Therefore it is necessary to evaluate how a reservoir ecosystem changes, and how serious or reversible these changes are (Scheffer \& Carpenter 2003). To

14 protect and manage these systems, the WFD requires European Union member states to assess the ecological potential of their HMWB using a holistic approach (European Commission 2000). The ecological status is defined according to the biological, chemical and physical characteristics of the water

17 bodies and their variation from reference cases. Research efforts over the last decade were mostly

18 dedicated to developing methodologies to assess the ecological status of natural water bodies (e.g.

19 WISER project http://www.wiser.eu or FAME project http://fame.boku.ac.at) but little effort addressed

20 other categories of water bodies such as HMWB, particularly reservoirs. The few assessment systems

21 developed for reservoirs have so far not been applied to an area larger than a single country (Jennings et

22 al. 1995; Navarro et al. 2009; Han et al. 2014). The evaluation of ecological quality is challenging

23 because reservoirs are complex systems that represent a transitional environment between lakes and rivers

24 (Wetzel 2001; Irz et al. 2002; Straškraba 2005) and usually do not have an undisturbed reference state. 
The variability of environmental conditions and diverse human uses create complex reservoirs and affect the organisms that inhabit these systems (Straškraba 2005). The morphology of a reservoir depends on that of the original river valley prior to damming and the depth of a reservoir usually increases

4 from the tributary to the dam. Big dams block the movements of fish, create unnatural flow regimes and 5 alter energy transport between aquatic and terrestrial environments. Three distinct morphological zones 6 occur in reservoirs: riverine, transition and lacustrine zone (Wetzel 2001). Each zone is inhabited by

7 specific biota that contribute to the complexity of the ecosystem. In addition the WFD states that management of reservoirs for human uses is a component of the functioning of the system and cannot be considered as a stressor (European Commission 2000). Due to all these characteristics, reservoirs have functions that are not comparable to natural lakes (Launois et al. 2011b) and thus merit specific scientific focus.

The WFD emphasizes the central role of four biological groups to assess the health of aquatic ecosystems: flora, benthic invertebrates, fish fauna, and phytoplankton. While fish in general are sensitive to a variety of natural and disturbance factors (Karr 1981; Karr et al. 1986), each species can also have its own impact on the biological processes in aquatic ecosystems (Carpenter et al. 1985). The lifespan of fish is long enough to integrate long-term changes and they are also sensitive to acute harmful events in

17 ecosystems. Through their mobility and presence at different trophic levels, fish provide an integrative 18 view of the ecosystem (Lindeman 1942; Karr et al. 1986). The species composition of fish communities 19 may differ between locations but functional composition offers a way to easily compare communities on a 20 wider scale (Logez et al. 2013). Finally, fish are a highly visible component of the aquatic community to the public and the combination of commercial and recreational fisheries suggests that fish are more

22 suitable than any other biota to guide management strategies to improve ecological quality. 
1 enables the prediction of expected metric values in the absence of pressure data for each reservoir based

2 on their environmental characteristics was used (Baker et al. 2005; Kilgour \& Stanfield 2006). Once the

3 environmental variability of metrics was controlled, the metrics most sensitive to human pressures were

4 selected and combined into a final index that can be applied to identify restoration priorities and improve

5 ecosystem health (Pont et al. 2006; 2007; Argillier et al. 2013).

\subsection{Dataset}

10 The database contains information from 124 French and 20 Czech fish sampling campaigns in different

11 reservoirs (Fig. 1, Table A1 in Supporting Information) covering 6 ecoregions (Illies 1978). In reservoirs

12 with multiple years of sampling, only the most recent data was used.

\subsection{Fish sampling}

15 The fish communities were sampled by benthic gillnets from 2005 to 2013 during the period between July

16 and the middle of October. Depth stratified sampling, together with total effort derived from reservoir

17 area, and maximum depth were applied as recommended by CEN (2005). For instance, in reservoir with a

18 maximum depth of $4 \mathrm{~m}$ and area $0.4 \mathrm{~km}^{2}$, the number of nets used was 7 , whereas in reservoir with a

19 maximum depth $30 \mathrm{~m}$ and area $1.4 \mathrm{~km}^{2}$ the maximum number was 80 . Benthic gillnets, $30 \mathrm{~m}$ in length,

$201.5 \mathrm{~m}$ in height, and composed of 12 panels with mesh sizes ranging from 5 to $55 \mathrm{~mm}$ knot-to-knot were

21 used. The gillnets were set before sunset and lifted after sunrise to cover maximal peaks of fish activity

22 (Prchalová et al. 2010). All age categories were taken into account during analyses, including young-of-

23 the-year. Fish were identified to species level, measured to total length and weighed. The abundance and

24 biomass were expressed as catch (number of individuals) and biomass (grams) per unit effort (1000 $\mathrm{m}^{2}$

25 night $^{-1}$ ), hereafter referred to as CPUE and BPUE. 


\subsection{Fish metrics}

Functional and taxonomic metrics were developed by a panel of experts during the WISER project based on the known taxonomy and biology of each species (Caussé et al. 2011; Argillier et al. 2013) (Table A2 in Supporting Information). The metrics were defined to evaluate abundance, composition and age structure of fish communities as required by the WFD. The abundance metrics were total fish abundance and biomass (total CPUE and total BPUE). Composition metrics included the Shannon diversity index and fish classified to families, reproductive, trophic, feeding habitat and tolerance guilds. The family and guild metrics were expressed in CPUE, BPUE and the proportion of total CPUE and BPUE. The age structure was indirectly assessed by average fish weight. Unidentified fish (e.g. Abramis sp. or Cyprinidae unknown) and hybrids were excluded in the calculation of diversity and guild metrics but were kept for the calculation of total abundance and biomass. more than $60 \%$ of reservoirs were used, and total of 57 metrics were computed. Due to their skewed distribution, metrics expressed in CPUE, BPUE and average weight were log-transformed $\left(\log _{\mathrm{e}}(\mathrm{x})\right)$ or, $\log _{e}(x+\min (x))$ to handle zero values. The proportion metrics were arcsine square-root transformed.

\subsection{Environmental and pressure variables}

19 The environmental conditions in reservoirs were characterized by five environmental variables

20 influencing fish communities (Table A1 in Supporting Information).

21 Average yearly air temperature was used because many biological and ecological processes are

22 temperature-dependent. The average yearly air temperature was computed from monthly mean

23 temperatures based on the University of East Anglia's Climatic Research Unit database (New et al. 2002).

24 Catchment area, reservoir area and maximum depth were selected due to their documented positive

25 relationships with fish species richness (Eckmann 1995; Jeppesen et al. 2000; Irz et al. 2002, 2007;

26 Brucet et al. 2013). Moreover, the area and depth of a water body determines the composition of the 
1 whole community (Holmgren \& Appelberg 2000; Jeppesen et al. 2000; Irz et al. 2002; Olin et al. 2002;

2 Mehner et al. 2005). These three parameters were either measured in the field, extracted from

3 topographical maps or estimated using geographic information systems (GIS).

4 The theoretical retention time was computed as volume (obtained similarly as others geographic

5 parameters) divided by discharge measured for a long-term period ( $>20$ years).

6 The environmental variables, with the exception of temperature, were $\log _{\mathrm{e}}$-transformed to achieve

7 normality, linearity and homogeneity of variance assumptions. eutrophication (Brucet et al. 2013; Argillier et al. 2013; Birk et al. 2012), total phosphorus concentration

10 (TP) $\left(\mu \mathrm{g} \mathrm{l}^{-1}\right)$ was used as a measure of eutrophication level. The concentration was expressed as an average based on at least three samples in the euphotic layer in different seasons. The percentage of agricultural land use in the catchment (AgriA) was used as a second evaluation of pressure occurring in reservoirs. AgriA data were obtained from the Corine Land Cover database

14 (http://www.eea.europa.eu/publications/COR0-landcover). The TP and AgriA were transformed using 15 logarithm and arcsine square-root transformation respectively.

\section{$17 \quad 2.5$ Metric modelling}

18 The metrics were evaluated through a selection procedure (Pont et al. 2006; 2007; Argillier et al. 2013) to ensure that their environmental variability could be sufficiently controlled, that they responded to at least one of the two pressure variables, and that the correlations between the final set of metrics were limited. 
The reservoirs in the training data set were used to calibrate the multiple linear regressions relating observed metric values to environmental and pressure values (Argillier et al. 2013). The square of

3 the parameters of all environmental variables and pressures were also added in the model as the

4 relationship between metrics and environmental variables can be nonlinear. A stepwise procedure was 5 used to select the best set of explanatory variables to explain each metric, based on Akaike information

6 criterion (AIC). Only multiple linear regressions which respected the assumptions of error normality and

7 lack of high leverage effects were kept. Finally, metrics for which at least $30 \%$ of their variance could be explained by the global model and if $10 \%$ of the metric variance could be explained by one single

9 pressure were retained (partition of variation based on $\mathrm{R}^{2}$, Borcard et al. 1992).

11 the relationship between predicted and observed metric values is unbiased it should follow a linear

12 function: $\mathrm{y}=\mathrm{x}$. Therefore the intercept and the slope of the linear regression between observed and

13 predicted metric values equal to 0 and 1 respectively were tested.

To assess the sensitivity of each metric to pressures it was necessary to control their variability due to

17 environmental conditions. This was performed for each metric using multiple linear regressions to predict 18 the theoretical values observed for $10 \%$ of AgriA and $20 \mu \mathrm{g} \mathrm{l}^{-1}$ of TP (Caussé et al. 2011; Brucet et al.

19 2013). The level of degradation of a reservoir was obtained by the deviation between observed (OBS) and 20 theoretical (THEO) metric values: DEV = OBS - THEO. Following Hering et al. (2006), these deviations 21 were derived into an ecological quality ratio (EQR) where an increase of metric values was observed with 22 increasing pressures:

$23 E Q R=1-\frac{D E V-\text { lower anchor }}{\text { upper anchor - lower anchor }}$

24 Where the lower anchor was the minimum DEV observed among the whole data set, and upper anchor the 25 maximum DEV. EQRs vary between 0 reflecting a high level of impairment and 1 no degradation. 
The metric sensitivity was assessed by measuring the correlation between metric EQRs and pressure variables. A pressure index (PI) condensing the two pressures into one variable was also computed by first scaling each pressure between 0 and 1 and then averaging these scaled pressures. A metric was considered to be sensitive if the Spearman's rank correlation coefficient ( $\rho$ ) between EQRs and pressures (including PI) was greater than 0.4 .

2.7 Metric redundancy

8 To limit the redundancy between metrics, only metrics with correlations between each other lower than

90.8 were selected. If two metrics were redundant, the metric with the highest $\rho$ with PI was retained.

12 To select the best set of metrics, all combinations of averaged metrics were tested and the combination with the highest correlation with the PI was chosen as the aggregated fish index (FI). combination $100 \mu \mathrm{g} 1^{-1} \mathrm{TP}$ and $50 \%$ AgriA).

The range of FI was divided into five ecological potential categories (maximum, good, moderate, poor, and bad) to define the ecological classes. Reservoirs with almost no impacts were designated to have maximum ecological potential, with a very low PI and high FI $(\geq 0.8)$. For the next four categories

21 the FI ranges were FI = 0.79-0.6, 0.59-0.4, 0.39-0.2, <0.19 respectively (European Commission 2000).

22 The difference between three classes of PI and five categories of ecological potential were evaluated by

23 Kruskal-Wallis one-way ANOVA followed by Tukey HSD post-hoc test. All statistical analyses were

24 performed using R statistical software (R version 3.0.1) (R Development Core Team 2013) using

25 packages ade4 (Dray \& Dufour 2007), MASS (Venables \& Ripley 2002), car (Fox \& Weisberg 2011),

26 hier.part (Walsh \& Nally 2013) and doSNOW (Analytics \& Weston 2014). 
3. Results

3.1 Fish data

In the 144 French and Czech reservoirs (Figure 1, Table A1 in Supporting Information) 45 fish species were captured (Table A2 in Supporting Information). The number of species varied between four and 18 per reservoir. The most common species were perch (Perca fluviatilis) and roach (Rutilus rutilus), which occurred in $98 \%$ and $97 \%$ of reservoirs, followed by pikeperch (Sander lucioperca), bream (Abramis brama), rudd (Scardinius erythrophthalmus), pike (Esox lucius), ruffe (Gymnocephalus cernua) and white bream (Blicca bjoerkna) (all in $>60 \%$ of reservoirs). Alternatively, $22 \%$ of species occurred only in one reservoir and another $29 \%$ in less than $5 \%$ of reservoirs (Table A2 in Supporting Information). The relative biomass and abundance of species were closely related to their occurrence, with a clear dominance of the five most common species (Table A2 in Supporting Information). The Shannon diversity index was relatively low with differences for biomass and abundance (an average of 1.58 and 1.28 , respectively). The average fish weight was $63.0 \mathrm{~g}$.

17 richness and distribution in all the reservoirs was Cyprinidae, which accounted for $60 \%$ of species. Although only three species belonged to the family Percidae, the family was nonetheless present in all the reservoirs sampled. The third most common family was Esocidae, which was represented by pike. In Europe, the family Salmonidae was represented in the dataset by six species, but they occurred in only $21 \quad 14 \%$ of reservoirs. guild was the phyto-lithophilic guild which represented $24 \%$ of species and occurred in all the reservoirs.

24 Phytophilic was the second most common guild with $24 \%$ of species and a $99 \%$ occurrence, while

25 litophils comparised the third most frequently occurring reproduction guild with $42 \%$ of species 26 occurring in $65 \%$ of reservoirs. 
Seven trophic guilds were also recorded (Table A2 in Supporting Information). The omnivore

trophic guild was present in all the reservoirs and the invertivore/piscivore guild was also very common (98\% occurrence). The third and fourth most common guilds included piscivorous and planktivorous fish with occurrences in $95 \%$ and $86 \%$ of reservoirs, respectively. Both types of feeding habitat were similarly present in reservoirs, with the open water guild present in $100 \%$ of reservoirs and the benthic guild present in $99 \%$ of reservoirs.

The final classification of species was based on tolerance to any stressors related to reservoirs morphology, hydrology or water chemistry. The difference in proportion of tolerant and intolerant species was low (36\% and $22 \%$ ). The tolerant species were present in $99 \%$ of reservoirs, and intolerant fish in $17 \%$.

The total catch expressed by total BPUE and CPUE was highly variable. The total fish biomass in

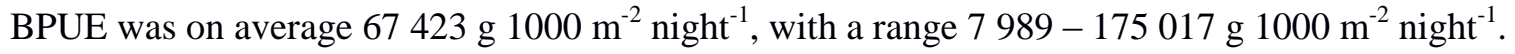
Average abundance was 1562 ind. $1000 \mathrm{~m}^{-2}$, with a range $58-5688$ ind. $1000 \mathrm{~m}^{-2}$ night $^{-1}$.

\subsection{Metrics selection and development of the fish index}

The modelling procedure excluded $72 \%$ of the tested metrics (the first statistical procedure performed).

The validation subset and procedure identified seven metrics where the intercept and slope of the linear regression between observed and predicted values did not differ significantly from 0 and 1 . All reproductive guilds, fish families, average weight and index of diversity failed to pass the selection criteria. The percentage of planktivorous fish based on CPUE was the only proportion metric to be retained. The other six metrics were based on direct BPUE (total, omnivorous and tolerant fish) and CPUE (invertivores/piscivores, planktivores and feeding in open water fish).

The Spearman correlation coefficients between the seven candidate metrics that were transformed into EQRs, both stressors, and the PI were always negative. In other words, EQR values decreased with increasing pressure values as expected. Among the candidate metrics, BPUE of omnivorous fish was 
eliminated due to low correlation to PI $(|\rho|<0.40)$. At this step six metrics remained as candidate metrics

2 for the FI.

The total BPUE and BPUE of tolerant fish were both $\rho=0.89$, and the CPUE of planktivorous fish and the percentage abundance of planktivorous fish were also the same $(\rho=0.81)$. Due to metric redundancies, total BPUE and CPUE of planktivorous fish were retained since they have higher absolute correlation coefficients with PI, $\rho=-0.59$ and -0.50 respectively. The two remaining fish metrics, CPUE of fish feeding in open water and CPUE of invertivorous/piscivorous fish, were $\rho=-0.41$ and -0.40 with PI and $\rho<0.40$ with other metrics.

The EQRs of the four selected metrics were combined and their scaled average was tested in for selected metrics used both pressure variables, the number of environmental variables was one to three and the amount of explained variability ranged between 63.3 and $35.6 \%$ (Table 1). When these three metrics were used for FI, the plot of the relationship between FI and PI was well distributed without evident outliers (Fig. 2). $\mathrm{p}<0.001$ ). All three classes differed significantly from each other (Tukey HSD, $\mathrm{p}<0.001$ ).

\subsection{Setting class boundaries}

The classes of ecological potential were significantly different (Fig. 4, Kruskal-Wallis test: $\mathrm{H}_{4,144}=$ this classification, we categorized nine reservoirs in the maximum ecological class, 34 in the good

24 ecological class, 52 reservoirs in the moderate ecological class, 42 in the poor, and seven in the bad

25 ecological classes (Table A1 in Supporting Information).The fish index did not show a significant

26 difference between the French and Czech reservoirs (Fig. 5, Kruskal-Wallis test: $\mathrm{H}_{1,144}=2.65$, p>0.1). 
A new fish index applicable to Central and Western European reservoirs was developed and is likely to be transferable in other European ecoregions. This fish index functions as an intermediate category between continental and national indices as the maximum distance between two reservoirs in the present analysis was $1674 \mathrm{~km}$. The index was developed using a site-specific approach, similar to the European index used for lakes (Argillier et al. 2013). The index is composed of three fish metrics and reflects the degradation of the water ecosystems due to eutrophication. The robustness of the index allows general applicability to reservoirs with environmental and pressure conditions such as used in this study. Fish metrics were defined mainly as functional ecological guilds allowing the evaluation of fish communities in similar way even if species composition varied (Logez et al. 2013).

Three selected metrics is a reasonable quantity in the context of assessment methodologies of other biological elements in Europe (Birk et al. 2012). The low number of selected metrics can be explained by the low specialization of dominant lentic fish species in Europe. They have broad ecological niches and flexible life-histories due to historical processes such as glaciations (Tonn et al. 1990; Griffiths 2006) and this makes them less vulnerable to anthropogenic stressors. Moreover, most of these species are

17 considered as tolerant species, confirmed by a high correlation between the total BPUE and BPUE of tolerant fish. Indices based on relatively tolerant faunas very often lead to the selection of a few core metrics. This is the case of Mediterranean areas that exhibit highly fluctuating environmental conditions and thus harsh environments for all organisms. In these areas, fish are generally tolerant to cope with the

21 heterogeneity of the ecosystems. Such tolerance could limit both the amount of metrics available and their 22 responsiveness to pressures (Pont et al. 2007). Therefore it is not so surprising that the number of metrics 23 finally retained is low when dealing with relatively tolerant fish faunas (Magalhães et al. 2008). 
2000; Søndergaard et al. 2005; Launois et al. 2011a,b; Kelly et al. 2012; Argillier et al. 2013). The second

selected metric, CPUE of planktivorous fish, was referred by Launois et al. (2011a,b) to be a good indicator of agricultural impact on French water bodies. The metric is composed of three species, including one of the most common species, common bream. This species was used in several fish indices as a single-species indicator of ecosystem degradation (Mehner et al. 2005; Garcia et al. 2006; Kelly et al. 2012). The last selected fish metric in fish index was CPUE of invertivorous/piscivorous fish. Although, it includes six fish species, the most important are perch and pikeperch. Pikeperch is a typical species for lowland nutrient rich water-bodies (Gassner et al. 2005) and its population increases with eutrophication (Kitchell et al. 1977; Mehner et al. 2005). Small individuals of the third most common species in the dataset, perch, were also recognized to increase in abundance with productivity of the water system (Mehner et al. 2005).

In most of the cases, reservoirs have been classified by European Member States as heavily modified water bodies. Therefore, their hydro-morphological alteration in relation with their use must be taken into account as a constraint preventing the assignment of good ecological status and justifying less stringent quality requirements (European Commission 2000). We demonstrate here that even if fish assemblages are impacted by hydro-morphological stressors associated with water use, and likely influenced by fisheries management (Boukal et al. 2012; Vašek et al. 2013), the established fish populations and their parameters closely reflect the intensity of eutrophication. This is in general agreement with other fish indexes developed for European lakes (Argillier et al. 2013) and rivers (Pont $e t$ al. 2006, 2007).

After considering all aspects of the current dataset, the maximum ecological class was set to reservoirs considered as being near their reference status. Not surprisingly, the maximum ecological potential class was rarely observed. In Central and Western Europe human activity in recent centuries has affected most areas. Only at nine locations did reservoirs recover to reach their maximum ecological potential. The good ecological potential class was also not frequently observed. Most reservoirs had moderate and poor ecological potential. The final class, bad ecological potential, was very rare as well. 
This was in general agreement with our field experiences. In summary, artificial water bodies suffer from eutrophication; however, in the majority of reservoirs the situation is not critical but they still deserve our

3 attention.

The comparison of index ranges between the French and Czech reservoirs shows that the ecological quality of reservoirs is comparable in both countries. It seems that Czech reservoirs are in slightly better condition (although no significant difference between countries was found). It could be attributed to the geographical position of the Czech Republic in Central Europe and the location of its reservoirs in the upper parts of rivers. The other reason could be the much smaller dataset from the Czech Republic, and the associated probability that the most degraded reservoirs in the country are missing from the dataset.

Unexplained variability in the selected models ranged from 37 to $63 \%$. It suggests that the models could be improved by adding other variables not used in this study. First, the parameters characterizing human activities in reservoirs should be collected. Until now, we have faced difficulties in collecting this data from reservoir managers.

Although we are aware of limitations of the index developed, it is ecologically meaningful and fulfils two criteria of WFD - abundance and composition. One metric to assess age structure was used in

17 the statistical process but was not identified as a significant parameter (average weight). The relationship 18 between size structure and productivity was found in small scale, e.g. northern German lakes (Emmrich et al. 2011) and near Danish lakes (Jeppesen et al. 2000), but it has not been identified as being important on a large geographic scale (Brucet et al. 2013; Emmrich et al. 2014). The reason for different size structure

21 is dependent on temperature rather than productivity (Emmrich et al. 2014).

23 conclude that it is applicable to all European states, with similar environmental conditions as used in this

24 study that must meet the requirements stated by WFD with an interest in improving the ecological health 25 of their reservoirs. The reliability of the index was confirmed by all validation procedures. It is a practical 
tool to be used in cases where datasets are limited and as the basis for further collaboration amongst

partners.

\section{Acknowledgements}

We thank the many people and agencies who provided environmental, pressure and fish data, especially FishEcU members (www.fishecu.cz), ONEMA and French Water Agencies; Reynaud N. and Point T. for their excellent stewardship of databases; Tse L. and Dr. Welcomme for revision of the English. We also thank the editor and three anonymous reviewers for their helpful suggestions. Ricard D. was supported by project Postdok_BIOGLOBE (CZ.1.07/2.3.00/30.0032) co-financed by the European Social Fund and the state budget of the Czech Republic. This study was supported by project CEKOPOT (CZ.1.07/2.3.00/20.0204), co-financed by the European Social Fund the state budget of the Czech Republic and by the University of South Bohemia (145/2013/P).

\section{References}

Analytics R. \& Weston S. (2014) doSNOW: Foreach parallel adaptor for the snow package. R package version 1.0.12. http://CRAN.R-project.org/package $=\mathrm{doSNOW}$

Argillier, C., Caussé, S., Gevrey, M., Pédron, S., De Bortoli, J., Brucet, S., Emmrich, M., Jeppesen, E., Lauridsen, T., Mehner, T., Olin, M., Rask, M., Volta, P., Winfield, I., Kelly, F., Krause, T., Palm, A. \& Holmgren, K. (2013) Development of a fish-based index to assess the eutrophication status of European lakes. Hydrobiologia 704, 193-211.

Baker, E.A., Wehrly, K.E., Seelbach, P.W., Wang, L., Wiley, M.J. \& Simon, T. (2005) A multimetric assessment of stream condition in the northern lakes and forests ecoregion using spatially explicit statistical modeling and regional normalization. Transactions of the American Fisheries Society 134, 697-710.

Belpaire, C., Smolders, R., Auweele, I. V., Ercken, D., Breine, J., Thuyne, G. Van \& Ollevier, F. (2000) An Index of Biotic Integrity characterizing fish populations and the ecological quality of Flandrian water bodies. Hydrobiologia 434, 17-33.

Birk, S., Bonne, W., Borja, A., Brucet, S., Courrat, A., Poikane, S., Solimini, A., van de Bund, W., Zampoukas, N. \& Hering, D. (2012) Three hundred ways to assess Europe's surface waters: An almost complete overview of biological methods to implement the Water Framework Directive. Ecological Indicators 18, 31-41.

Borcard, D., Legendre, P. \& Drapeau, P. (1992) Partialling out the spatial component of ecological variation. Ecology 73, 1045-1055.

Boukal, D.S., Jankovský, M., Kubečka, J. \& Heino, M. (2012) Stock-catch analysis of carp recreational fisheries in Czech reservoirs: Insights into fish survival, water body productivity and impact of extreme events. Fisheries Research 119-120, 23-32.

Brucet, S., Pédron, S., Mehner, T., Lauridsen, T.L., Argillier, C., Winfield, I.J., Volta, P., Emmrich, M., Hesthagen, T., Holmgren, K., Benejam, L., Kelly, F., Krause, T., Palm, A., Rask, M. \& Jeppesen, E. (2013) Fish diversity in European lakes: geographical factors dominate over anthropogenic pressures. Freshwater Biology 58, 1779-1793. 
Carpenter, S.R., Kitchell, J.F. \& Hodgson, J.R. (1985) Cascading Trophic Interactions and Lake Productivity. BioScience 35, 634-639.

Caussé, S., Gevrey, M., Pédron, S., Brucet, S., Holmgren, K., Emmrich, M., De Bortoli, J. \& C., A. (2011) Deliverable 3.4-4: Fish indicators for ecological status assessment of lakes affected by eutrophication and hydromorphological pressures. Irstea, Aix-en-provance: 46 PP.

CEN (2005) Water quality - sampling of fish with multi-mesh gillnets. EN - 14757.

Dray S. \& Dufour A.B. (2007) The ade4 package: implementing the duality diagram for ecologists. Journal of Statistical Software. 22, 1-20.

Eckmann, R. (1995) Fish species richness in lakes of the northeastern lowlands in Germany. Ecology of Freshwater Fish 4, 62-69.

Emmrich, M., Brucet, S., Ritterbush, D. \& Mehner, T. (2011) Size spectra of lake fish assemblages: responses along gradients of general environmental factors and intensity of lake-use. Freshwater Biology 56, 2316-2333.

Emmrich, M., Pédron, S., Brucet, S., Winfield, I.J., Jeppesen, E., Volta, P., Argillier, C., Lauridsen, T.L., Holmgren, K., Hesthagen, T. \& Mehner, T. (2014) Geographical patterns in the body-size structure of European lake fish assemblages along abiotic and biotic gradients. Journal of Biogeography, in press.

European Commission (2000) Directive 2000/60/EC of the European Parliament and of the Council of 23 October 2000 establishing a framework for Community action in the field of water policy. Official Journal of the European Parliament L327, 1-82.

Fox J. \& Weisberg S. (2011) An \{R\} Companion to Applied Regression, 2nd Edition. http://socserv.socsci.mcmaster.ca/jfox/Books/Companion

Garcia, X.-F., Diekmann, M., Brämick, U., Lemcke, R. \& Mehner, T. (2006) Correlations between typeindicator fish species and lake productivity in German lowland lakes. Journal of Fish Biology 68, $1144-1157$.

Gassner, H., Wanzenbock, J., Zick, D., Tischler, G. \& Pamminger-Lahnsteiner, B. (2005) Development of a Fish Based Lake Typology for Natural Austrian Lakes $>50$ ha Based on the Reconstructed Historical Fish Communities. International Review of Hydrobiology 90, 422-432.

Griffiths, D. (2006) Pattern and process in the ecological biogeography of European freshwater fish. The Journal of animal ecology 75, 734-751.

Han, J.-H., Kim, B., Kim, C. \& An, K.-G. (2014) Ecosystem health evaluation of agricultural reservoirs using multi-metric lentic ecosystem health assessment (LEHA) model. Paddy and Water Environment 12, S7-S18.

Hering, D., Feld, C.K., Moog, O. \& Ofenbock, T. (2006) Cook book for the development of a Multimetric Index for biological condition of aquatic ecosystems: Experiences from the European AQEM and STAR projects and related initiatives. Hydrobiologia 566, 311-324.

Holmgren, K. \& Appelberg, M. (2000) Size structure of benthic freshwater fish communities in relation to environmental gradients. Journal of Fish Biology 57, 1312-1330.

Illies, J. (1978) Limnofauna Europaea. A checklist of the Animals inhabiting European Inland Waters, with Account of their Distribution and Ecology, 2nd editio. Stuttgart and Swets \& Zeitlinger, Amsterdam, 532 PP.

Irz, P., Laurent, A., Messad, S., Pronier, O. \& Argillier, C. (2002) Influence of site characteristics on fish community patterns in French reservoirs. Ecology of Freshwater Fish 11, 123-136. 
Irz, P., Michonneau, F., Oberdorff, T., Whittier, T.R., Lamouroux, N., Mouillot, D. \& Argillier, C. (2007) Fish community comparisons along environmental gradients in lakes of France and north-east USA. Global Ecology and Biogeography 16, 350-366.

Jennings, M.J., Fore, L.S. \& Karr, J.R. (1995) Biological monitoring of fish assemblages in Tennessee Valley reservoirs. Regulated Rivers Research Management 11, 263-274.

Jeppesen, E., Peder Jensen, J., Søndergaard, M., Lauridsen, T. \& Landkildehus, F. (2000) Trophic structure, species richness and biodiversity in Danish lakes: changes along a phosphorus gradient. Freshwater Biology 45, 201-218.

Karr, J.R. (1981) Assessment of Biotic Integrity Using Fish Communities. Fisheries 6, 21-27.

Karr, J.R., Fausch, K.D., Angermeier, P.L., Yant, P.R. \& Schlosser, I.J. (1986) Assessing biological integrity in running waters: a method and its rationale, (Vol. Special $\mathrm{Pu}$ ).

Kelly, F.L., Harrison, A.J., Allen, M., Connor, L. \& Rosell, R. (2012) Development and application of an ecological classification tool for fish in lakes in Ireland. Ecological Indicators 18, 608-619.

Kilgour, B.W. \& Stanfield, L.W. (2006) Hindcasting reference conditions in streams. American Fisheries Society Symposium 48, 623-639.

Kitchell, J.F., Johnson, M.G., Minns, C.K., Loftus, K.H., Greig, L. \& Olver, C.H. (1977) Percid Habitat: The River Analogy. Journal of the Fisheries Research Board of Canada 34, 1922-1935.

Launois, L., Veslot, J., Irz, P. \& Argillier, C. (2011a) Development of a fish-based index (FBI) of biotic integrity for French lakes using the hindcasting approach. Ecological Indicators 11, 1572-1583.

Launois, L., Veslot, J., Irz, P. \& Argillier, C. (2011b) Selecting fish-based metrics responding to human pressures in French natural lakes and reservoirs: towards the development of a fish-based index (FBI) for French lakes. Ecology of Freshwater Fish 20, 120-132.

Lindeman, R.L. (1942) The trophic dynamics aspect of ecology. Ecology 23, 399-418.

Logez, M., Bady, P., Melcher, A. \& Pont, D. (2013) A continental-scale analysis of fish assemblage functional structure in European rivers. Ecography 36, 080-091.

Magalhães, M.F., Ramalho, C.E. \& Collares-Pereira, M.J. (2008) Assessing biotic integrity in a Mediterranean watershed: Development and evaluation of a fish-based index. Fisheries Management and Ecology 15, 273-289.

Mehner, T., Diekmann, M., Brämick, U. \& Lemcke, R. (2005) Composition of fish communities in German lakes as related to lake morphology, trophic state, shore structure and human-use intensity. Freshwater Biology 50, 70-85.

Navarro, E., Caputo, L., Marcé, R., Carol, J., Benejam, L., García-Berthou, E. \& Armengol, J. (2009) Ecological classification of a set of Mediterranean reservoirs applying the EU Water Framework Directive: A reasonable compromise between science and management. Lake and Reservoir Management 25, 364-376.

New, M., Lister, D., Hulme, M. \& Makin, I. (2002) A high-resolution data set of surface climate over global land areas. Climate Research 21, 1-25.

Olin, M., Rask, M., Ruuhljärvi, J., Kurkilahti, M., Ala-Opas, P. \& Ylönen, O. (2002) Fish community structure in mesotrophic and eutrophic lakes of southern Finland: the relative abundances of percids and cyprinids along a trophic gradient. Journal of Fish Biology 60, 593-612.

Pont, D., Hugueny, B., Beier, U., Goffaux, D., Melcher, A., Noble, R., Rogers, C., Roset, N. \& Schmutz, S. (2006) Assessing river biotic condition at a continental scale: a European approach using functional metrics and fish assemblages. Journal of Applied Ecology 43, 70-80. 
Pont, D., Hugueny, B. \& Rogers, C. (2007) Development of a fish-based index for the assessment of river health in Europe: the European Fish Index. Fisheries Management and Ecology 14, 427-439.

Prchalová, M., Mrkvička, T., Kubečka, J., Peterka, J., Čech, M., Muška, M., Kratochvíl, M. \& Vašek, M. (2010) Fish activity as determined by gillnet catch: A comparison of two reservoirs of different turbidity. Fisheries Research 102, 291-296.

R Development Core Team, R. (2013) R: A Language and Environment for Statistical Computing. $R$ Foundation for Statistical Computing 1.

Scheffer, M. \& Carpenter, S.R. (2003) Catastrophic regime shifts in ecosystems: linking theory to observation. Trends in Ecology \& Evolution 18, 648-656.

Søndergaard, M., Jeppesen, E., Peder Jensen, J. \& Lildal Amsinck, S. (2005) Water Framework Directive: ecological classification of Danish lakes. Journal of Applied Ecology 42, 616-629.

Straškraba, M. (2005) Reservoirs and other Artificial Water Bodies. In: The Lakes Handbook: Lake Restoration and Rehabilitation, Volume 2. (eds P. OSullivan and C. Reynolds). lackwell Science Publ., Osney Mead, Oxford OX2 0EL, England, pp 300-328.

Tonn, W.M., Magnuson, J.J., Rask, M. \& Toivonen, J. (1990) Intercontinental Comparison of Small-Lake Fish Assemblages: The Balance between Local and Regional Processes. The American Naturalist $136,345-375$.

Vašek, M., Prchalová, M., Peterka, J., Ketelaars, H.A.M., Wagenvoort, A.J., Čech, M., Draštík, V., Říha, M., Jůza, T., Kratochvíl, M., Mrkvička, T., Blabolil, P., Boukal, D.S., Duras, J. \& Kubečka, J. (2013) The utility of predatory fish in biomanipulation of deep reservoirs. Ecological Engineering 52, 104 111.

Venables, W.N. \& Ripley, B.D. (2002) Modern Applied Statistics with S. 4th Edition.

Walsh, C. \& Nally, R.M. (2013) hier.part: Hierarchical Partitioning. R package version 1.0-4. http://CRAN.R-project.org/package=hier.part

Wetzel, R.G. (2001) Limnology: Lake and River Ecosystems, 3rd Editio (Vol. 37). 
Table 1: Models parameters for the three selected metrics. For each model the coefficients and significant environmental and pressures variables, results of statistics, variation partitioning and minimum and maximum deviance between observed and hindcast $(\mathrm{o}-\mathrm{h})$ values are shown $\left(\mathrm{p}<0.05^{*},<0.01 * *,<0.001\right.$ $* * *)$.

Fig. 1 Map of Europe indicating the position of the France and the Czech Republic (a) and the geographic distribution of the reservoirs included in the dataset in France (b) and in the Czech Republic (c), for details see Table A1 in the Supporting Information.

Fig. 2 Relationship between the Fish index developed in this study and the independently derived Pressure index used to determine the efficacy of the methodology in measuring anthropogenic impacts in highly modified water bodies.

Fig. 3 Distribution of the Fish index for low, moderate and high anthropogenically impacted reservoirs. Median values (thick lines), upper and lower quartiles (boxes), maximum and minimum values (whiskers), and outliers (dots) are shown.

Fig. 4 Distribution of the Pressure index for five classes of ecological potential. Median values (thick lines), upper and lower quartiles (boxes) and maximum and minimum values (whiskers) are shown.

Fig. 5 Distribution of the Fish index for reservoirs located in the Czech Republic and in France. Median values (thick lines), upper and lower quartiles (boxes) and maximum and minimum values (whiskers) are shown.

Table A1: Main characteristics of the French (FR) and Czech (CZ) reservoirs under investigation and their ecological classification based on the Fish index developed in this study. Abbreviations: average temperature (Avg T), reservoir catchment area (Catch A), theoretical retention time (TRT), concentration of total phosphorus (TP) and agriculture land cover (AgriA).

Table A2: Species relative frequency of occurrence in the dataset and guilds classification. Abbreviations of reproductive guilds: ARIAD -ariadnophilic, LITH - litophilic, OSTR - ostracophilic, PELA pelagiphilic, PHLI - phyto-lithophilic, PHYT - phytophylic, SPEL - speleophilic; Trophic guilds: BENT - benthivorous, HERB - herbivorous, INV - invertivorous, INV/PISC - invertivorous-piscivorous, OMNI - omnivorous, PISC - piscivorous, PLAN - planktivorous; Food habitat: BENT - benthic, WC open water; Tolerance guilds: TOL - tolerant, INTOL - intolerant and NULL - not classified. 


\begin{tabular}{|c|c|c|c|}
\hline & Total BPUE & $\begin{array}{l}\text { Invertivorous / } \\
\text { piscivorous } \\
\text { CPUE }\end{array}$ & Planktivorous CPUE \\
\hline Intercept & $9.81 * * *$ & $3.43 * * *$ & 1.08 \\
\hline$\%$ agriculture area & $2.50 * * *$ & $6.21 * * *$ & $1.17 *$ \\
\hline$\%$ agriculture area $^{2}$ & $-2.10 * * *$ & $-2.80 *$ & \\
\hline Total phosphorus & $0.20 * *$ & & $0.76 * *$ \\
\hline Maximum depth & $-2.54 * * *$ & & -0.37 \\
\hline Maximum depth ${ }^{2}$ & $1.07 *$ & & \\
\hline Theoretical retention time & $0.10 * * *$ & $0.45 * * *$ & -1.15 \\
\hline Theoretical retention time ${ }^{2}$ & & & -5.56 \\
\hline Reservoir area & & & $0.61 * * *$ \\
\hline Adjusted $\mathrm{R}^{2}$ & 0.633 & 0.370 & 0.356 \\
\hline $\begin{array}{l}\text { F-statistics and degrees of } \\
\text { freedom }\end{array}$ & $28.60_{6,90} * * *$ & $19.83_{3,93} * * *$ & $9.86_{6,90} * * *$ \\
\hline$\%$ variation due to pressures & 30.5 & 16.0 & 16.1 \\
\hline$\%$ variation due to environment & 13.2 & 24.9 & 8.1 \\
\hline $\begin{array}{l}\text { Range of values in used dataset } \\
\text { (min-max) }\end{array}$ & $\begin{array}{l}7989-175017(\mathrm{~g} \\
\left.1000 \mathrm{~m}^{-2} \text { night }^{-1}\right)\end{array}$ & $\begin{array}{l}2.8-3360.0 \text { (ind. } \\
1000 \mathrm{~m}^{-2} \text { night }^{-1} \text { ) }\end{array}$ & $\begin{array}{c}\text { 0-3 015.3 (ind. } 1000 \mathrm{~m}^{-2} \\
\text { night }^{-1} \text { ) }\end{array}$ \\
\hline Minimum deviance $\mathrm{o}-\mathrm{h}$ & -1.13 & -2.51 & -3.22 \\
\hline Maximum deviance o-h & 1.98 & 3.58 & 5.35 \\
\hline
\end{tabular}


b.
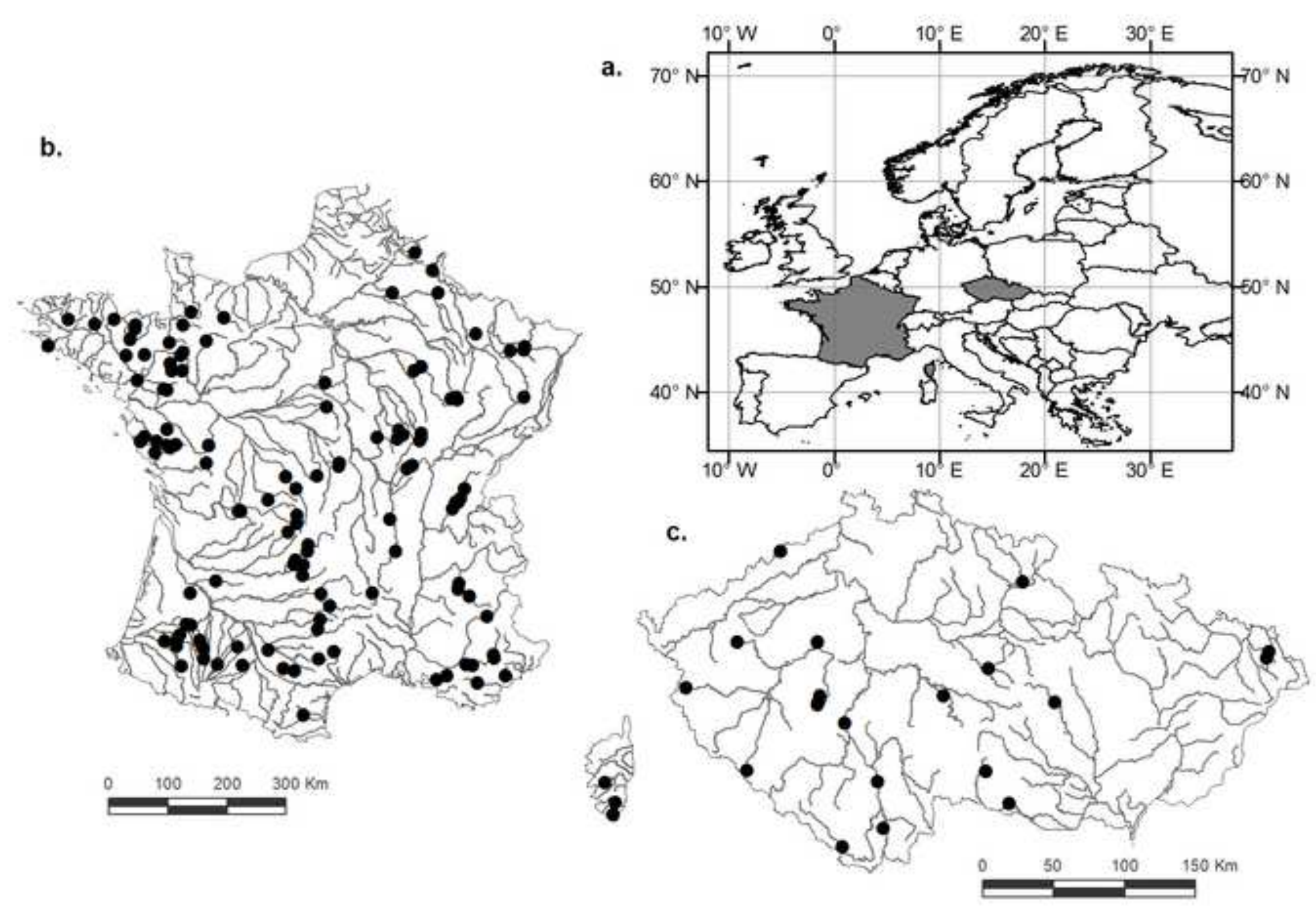


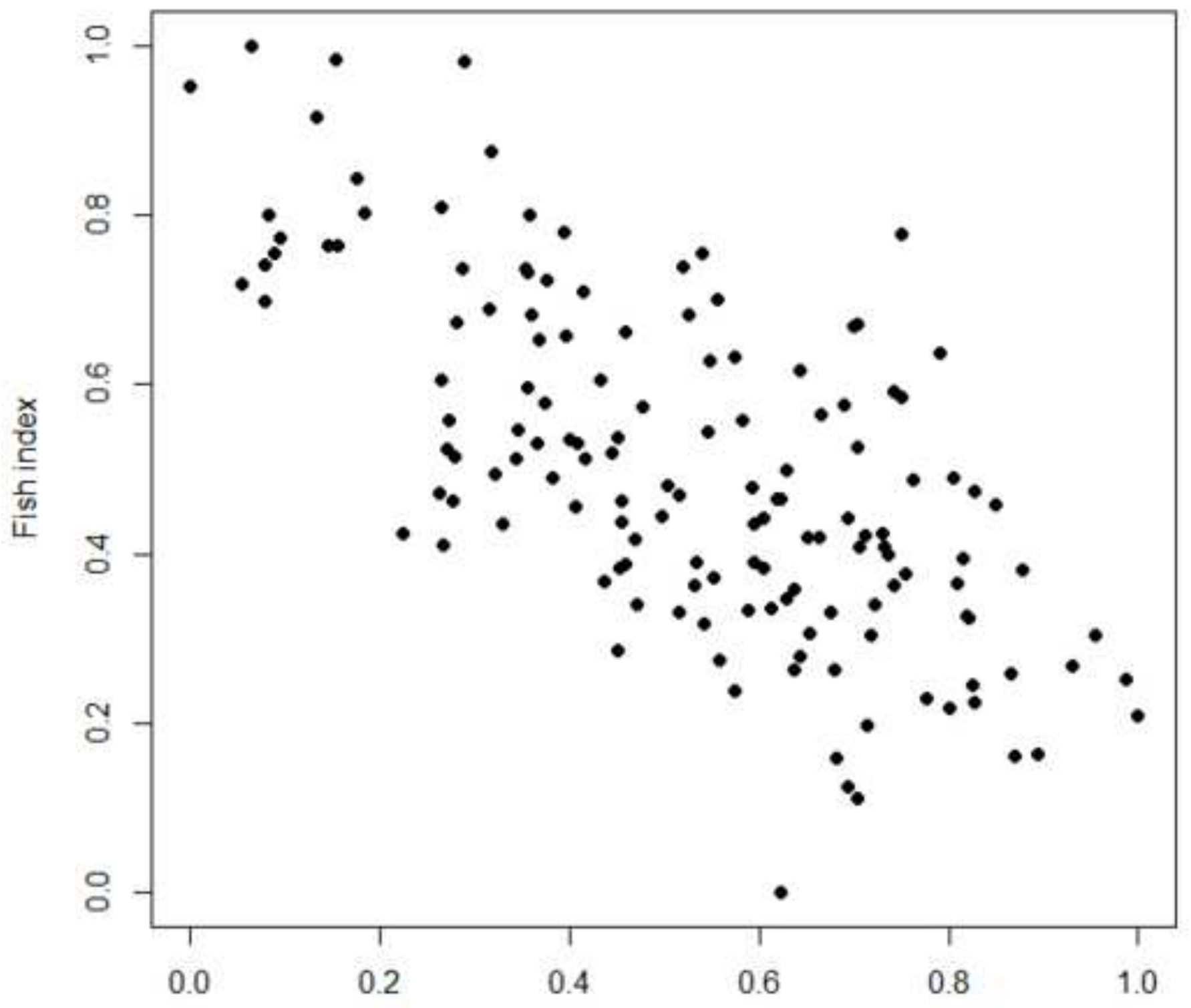

Pressure index 


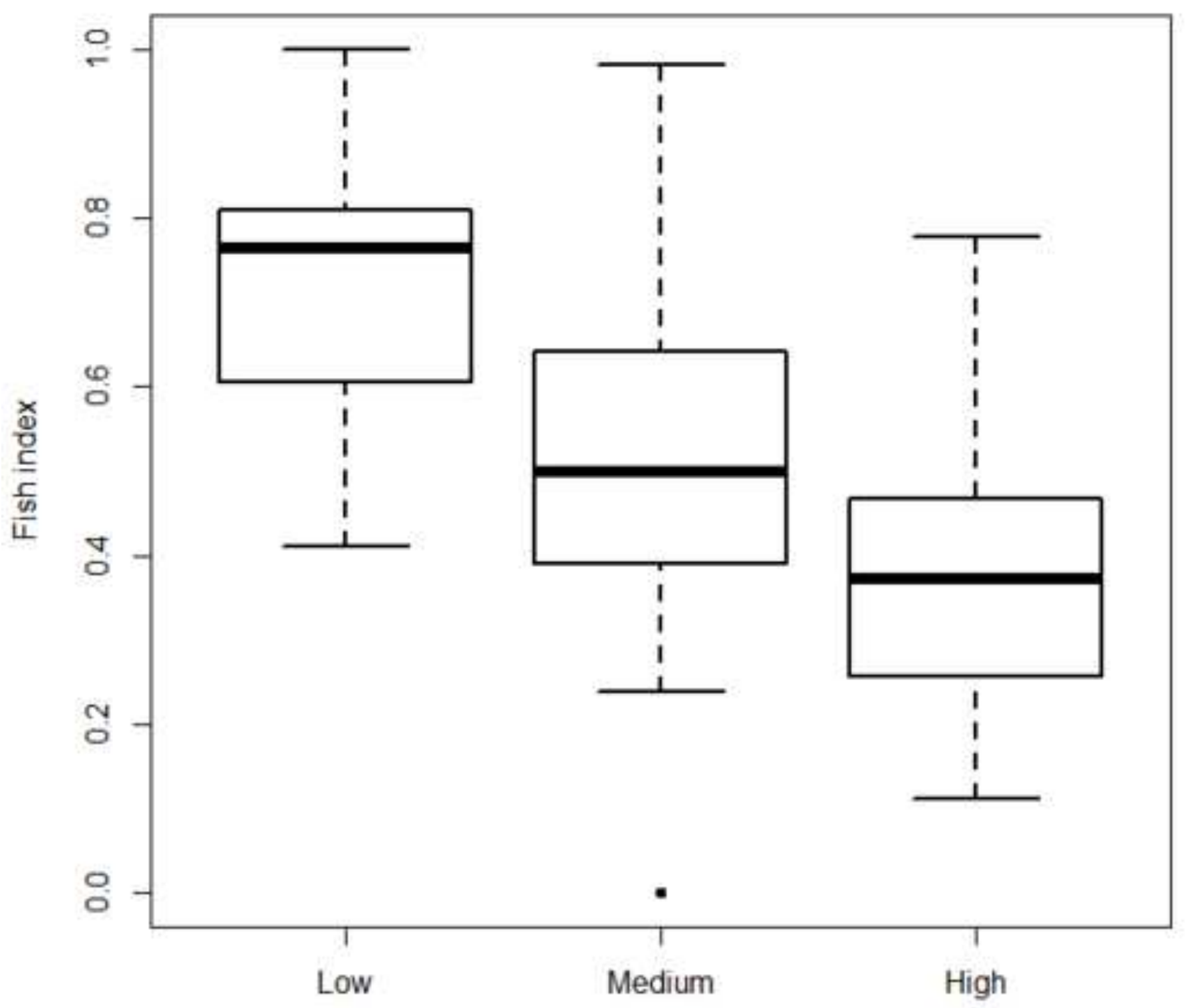

Anthropogenic impact 


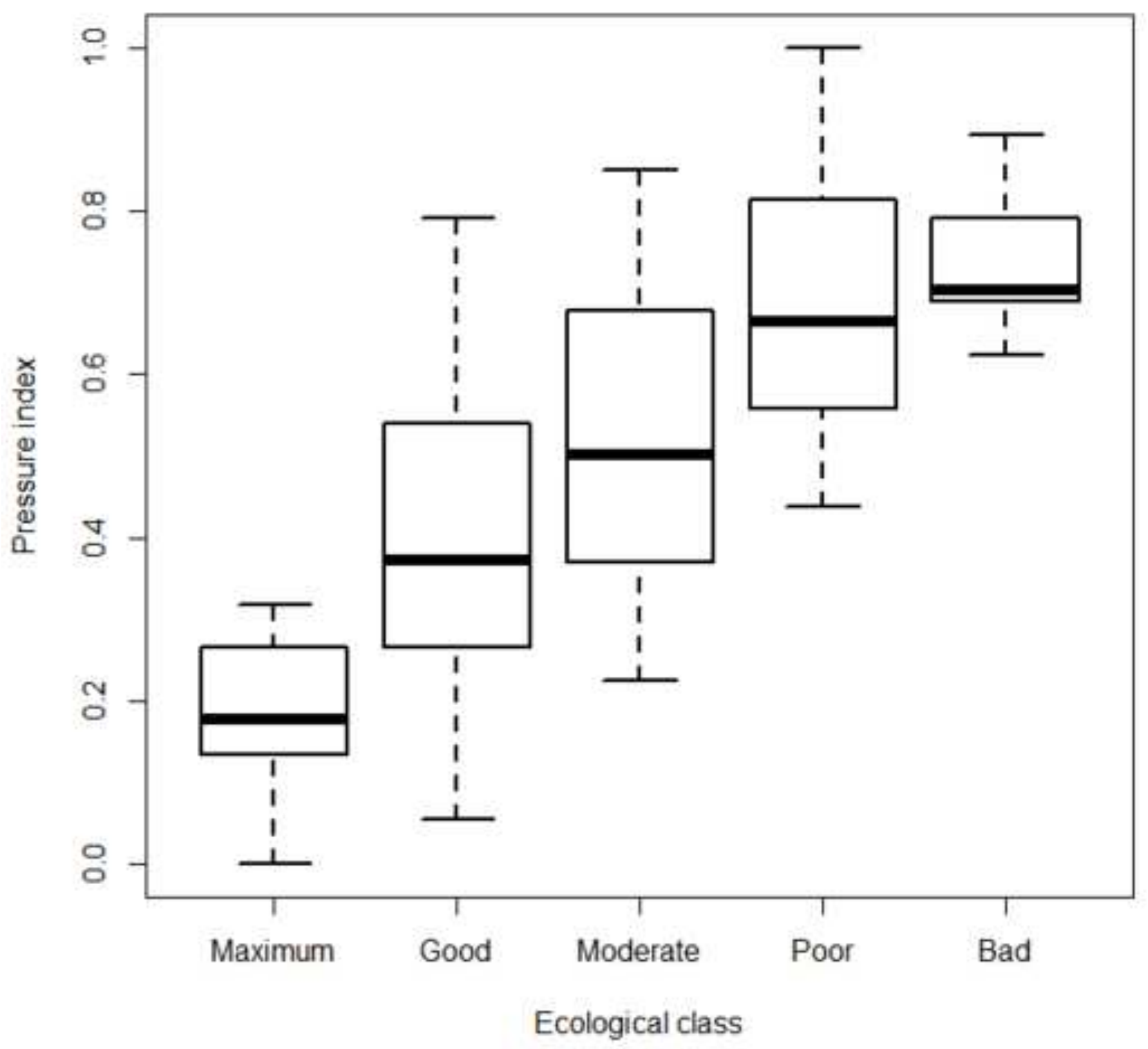




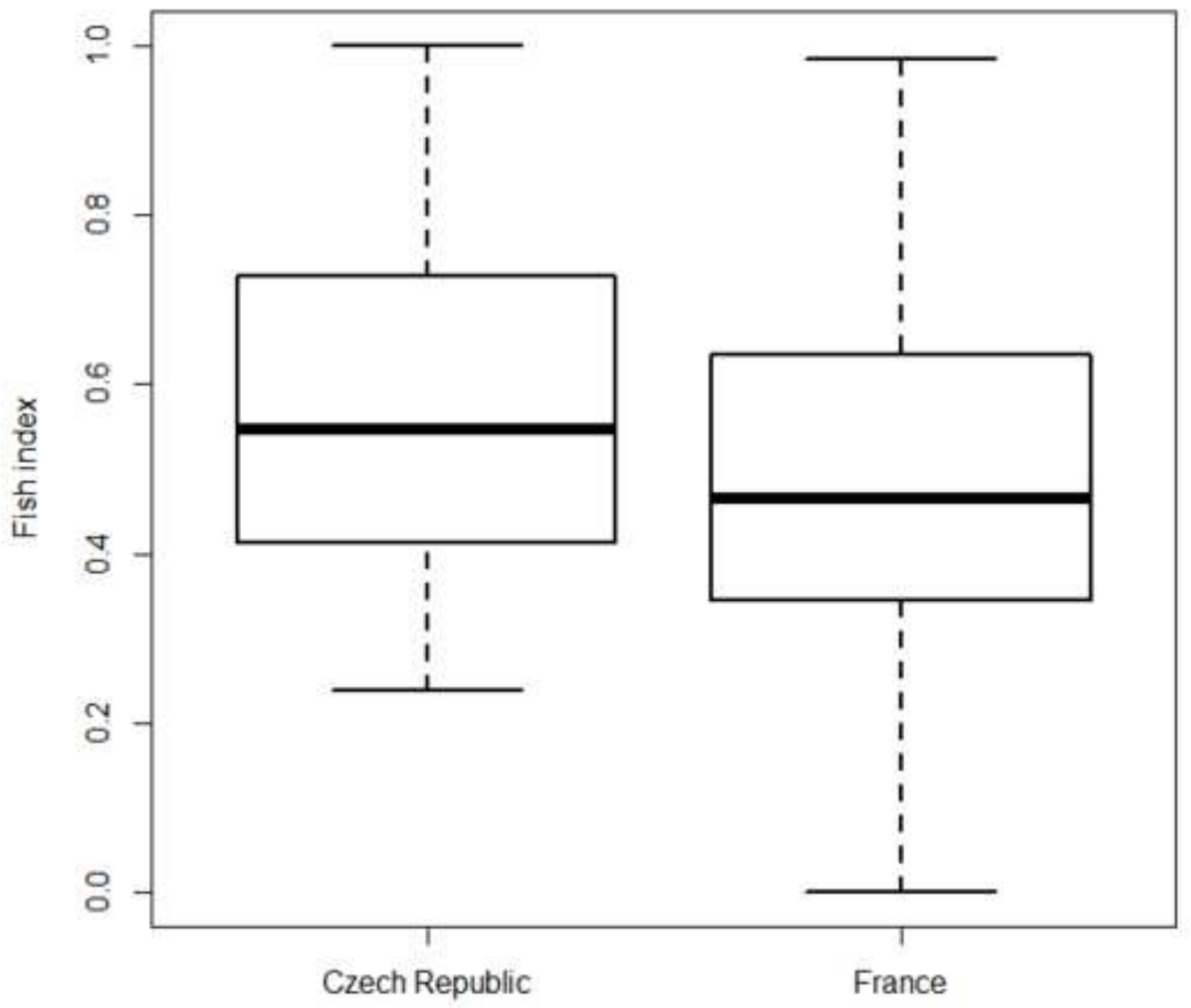


